\title{
SIMULAÇÃO DO PROCESSO SOLVAY NO LABORATÓRIO DIDÁTICO
}

\author{
Adriano L. de Araújo, Carlos A. Neves, Ana Maria C. Ferreira e Koiti Araki* \\ Instituto de Química - USP - Av. Prof. Lineu Prestes, 748 - CP 26.077 - 05599-970 - São Paulo - SP
}

Recebido em 2/12/96; aceito em 7/3/97

\begin{abstract}
SIMULATION OF SOLVAY PROCESS IN THE LABORATORY. The Solvay Process is an important route for the industrial preparation of sodium carbonate from brine and $\mathrm{CO}_{2}$. However, experiments illustrating such process are performed only in a few chemistry courses, mainly because of the difficulties to precipitate out the intermediate product $\mathrm{NaHCO}_{3}$ within the 3 or 4 hours generally available for laboratory classes. In this article we describe a method that properly simulates the Solvay process using glass apparatus that can be found in any chemistry laboratory. The good yields and purity attainable, associated with the short time ( 3 hours) required to get the sodium bicarbonate, account for the suitability of our method for chemistry or chemical engineering undergraduate students laboratory classes.
\end{abstract}

Keywords: Solvay process; simulation; sodium carbonate.

\section{INTRODUÇÃO}

O carbonato de sódio, também conhecido como barrilha, é um dos produtos químicos mais produzidos no mundo ${ }^{1}$. Nos EUA ocupava o $11^{\circ}$ lugar $^{2}$ em 1995, sendo superado por ácido sulfúrico, nitrogênio, oxigênio, amônia e etileno, entre outros. Em 1992, a capacidade instalada no $\mathrm{Brasil}^{3}$ era de 200.000 t/ano de $\mathrm{Na}_{2} \mathrm{CO}_{3}$. Sua importância pode ser verificada pelos inúmeros processos que utilizam o $\mathrm{Na}_{2} \mathrm{CO}_{3}$ como matéria-prima, como por exemplo, a fabricação de vidros, detergentes e sabões, papel, materiais cerâmicos, remédios, têxteis, etc. Atualmente, uma percentagem crescente da produção mundial de barrilha provém do processamento da trona ${ }^{4}, \mathrm{Na}_{2} \mathrm{CO}_{3} \cdot \mathrm{NaHCO}_{3} \cdot 2 \mathrm{H}_{2} \mathrm{O}$, encontrada principalmente nos Estados Unidos. Entretanto, o processo Solvay ainda continua sendo utilizado em outros países.

O processo Solvay foi desenvolvido integralmente pela engenhosidade e persistência de Ernest Solvay. Utilizando recursos próprios, fundou uma companhia de produção de $\mathrm{Na}_{2} \mathrm{CO}_{3}$ baseada no processo por ele desenvolvido. Inicialmente os resultados foram bem inferiores àqueles esperados, mas por meio do acompanhamento criterioso de todas as etapas envolvidas, os problemas foram sendo sanados um a um até resultar num processo eficiente e rentável. O processo utiliza como matérias-primas calcário e salmoura para produzir a barrilha e cloreto de cálcio como subproduto (Figura 1). O âmago do processo se encontra nas propriedades de $\mathrm{NH}_{3}$ e $\mathrm{CO}_{2}$ gasosos, que são utilizados para saturar a salmoura, e na diferença de solubilidade entre bicarbonato de amônio e bicarbonato de sódio produzidos na reação.

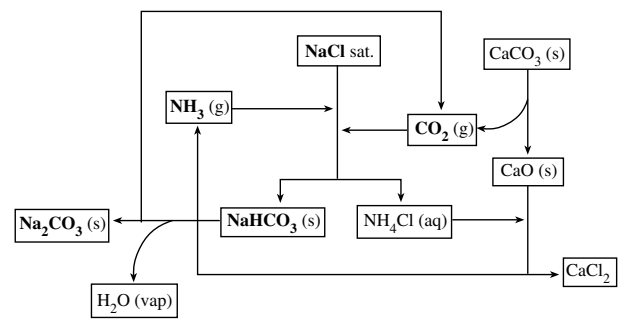

Figura 1. Esquema simplificado do Processo Solvay.

e-mail: koiaraki@quim.iq.usp.br.
Apesar da importância e simplicidade das reações envolvidas, são escassos os exemplos de experimentos didáticos que exploram a síntese do carbonato de sódio pelo processo Solvay ${ }^{5,6}$. Os exemplos encontrados invariavelmente utilizam processos em batelada, que pouca analogia têm com as operações unitárias verificadas no processo industrial contínuo ${ }^{1}$. Assim, nesse artigo descrevemos um novo arranjo, desenvolvido como projeto num curso de Química Inorgânica para Químicos, que permite reproduzir com fidelidade, utilizando materiais simples de laboratório, as etapas de amoniação e carbonatação da salmoura, seguidos da precipitação de $\mathrm{NaHCO}_{3}$ de elevada pureza e com bom rendimento. Esse tipo de experimento ilustra inúmeros conceitos fundamentais, como equilíbrios ácido-base, solubilidade, hidrólise, cálculos estequiométricos e reciclagem de reagentes. Além disso, a aparelhagem possibilita variar as temperaturas das colunas de amoniação e carbonatação e o fluxo relativo desses gases em relação ao fluxo de salmoura em contra-corrente. As características do experimento de simulação ora apresentado podem ser amplamente exploradas para a apresentação e discussão de vários conceitos importantes para a formação de químicos e engenheiros químicos.

\section{DESCRIÇÃO DA APARELHAGEM E PROCEDIMENTO}

Os processos de amoniação e carbonatação foram efetuados utilizando-se o método de fluxo em contra-corrente, em analogia ao processo industrial. A aparelhagem (Figura. 2) consta de duas colunas Vigreux de cerca de $20 \mathrm{~cm}$ de altura, com o maior número de indentações possíveis, para maximizar a superfície de contato. Essas colunas foram conectadas por meio de um separador do tipo campânula (detalhe Figura 2), que permite o escoamento da solução da coluna superior para a inferior por gravidade, mas impede a subida do $\mathrm{CO}_{2}$ para a coluna de amoniação. O separador é constituido de um tubo de cerca de $3 \mathrm{~cm}$ de diâmetro e $5 \mathrm{~cm}$ de extensão, em cujas extremidades foram adaptadas uma junta macho e uma fêmea. Um tubo aberto (tubo coletor) de cerca de $2 \mathrm{~cm}$ foi soldado à junta tipo macho. Esse tubo é parcialmente recoberto por um tubo de diâmetro maior (tubo selador), fechado na região intermediária e conectado à junta fêmea, que se encontra localizada num ângulo de $180^{\circ}$ em relação à junta anteriormente mencionada. Esse arranjo, semelhante a 
uma campânula, garante a formação de uma pequena coluna de líquido que impede o acesso do gás $\mathrm{CO}_{2}$ da coluna inferior à coluna superior, ao mesmo tempo que permite o escoamento da solução da coluna superior para a inferior. Pequenos orifícios na região do tubo selador, compreendido entre a base da junta fêmea e o selo, permitem a passagem do fluxo de gás amônia em direção à coluna de amoniação, ao mesmo tempo que garantem o livre escoamento da solução saturada de $\mathrm{NaCl}$ e amônia da coluna de amoniação para a coluna de carbonatação, através do separador.

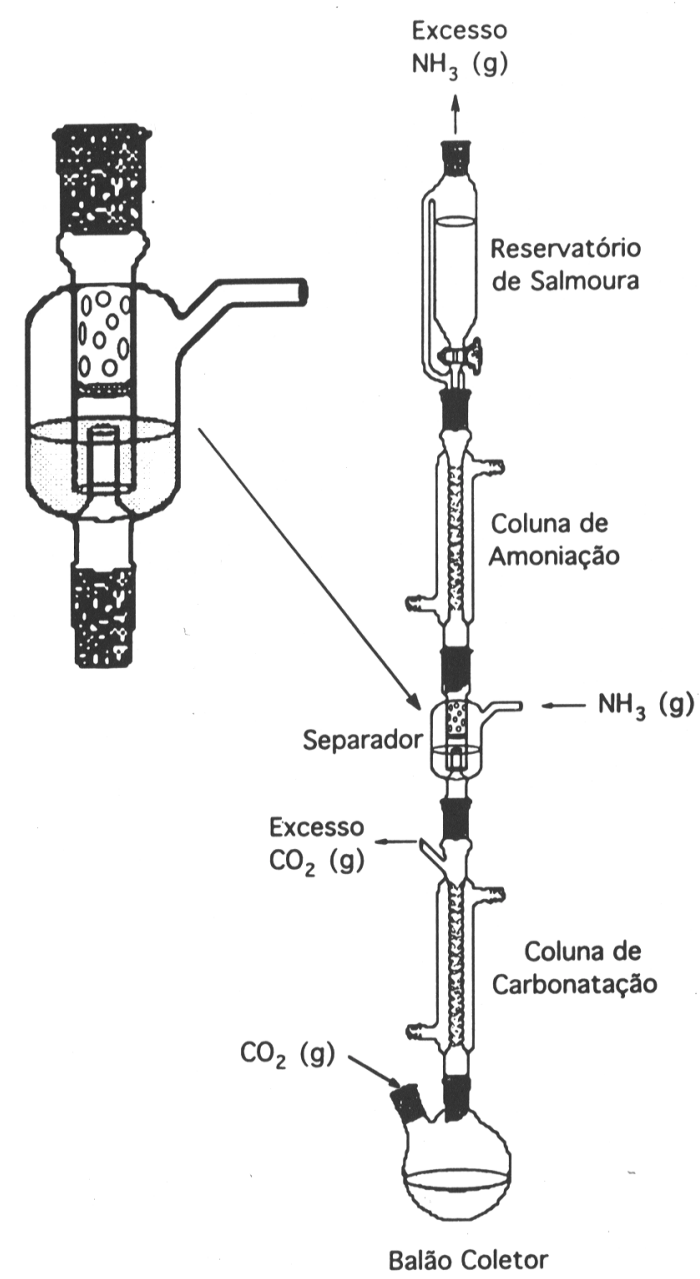

Figura 2. Esquema da aparelhagem completa utilizada para simular o Processo Solvay. São mostradas as colunas de amoniação e carbonatação, bem como o separador (também no detalhe), o reservatório de salmoura e o balão coletor.

$\mathrm{O}$ gás $\mathrm{CO}_{2}$ foi obtido por meio da sublimação do gelo seco e o gás $\mathrm{NH}_{3}$ foi gerado adicionando-se lentamente uma solução concentrada de amônia, contida num funil de adição, sobre pastilhas de $\mathrm{NaOH}$ ou KOH. O gás carbônico foi injetado a partir de uma saída lateral do balão coletor, que se encontra conectado à parte inferior da coluna de carbonatação. O excesso é eliminado através da saída lateral que se encontra no topo da coluna. $\mathrm{A} \mathrm{NH}_{3}(\mathrm{~g})$ foi injetada no sistema através do separador, sendo o excesso enviado para o funil de separação com equalizador de pressão contendo a salmoura (Figura 2).

O fluxo da solução de salmoura foi controlado em cerca de 60 gotas por minuto, ao mesmo tempo em que foram injetados o $\mathrm{CO}_{2}$ e o $\mathrm{NH}_{3}$ gasosos. A solução resultante foi resfriada em banho de gelo e água. O precipitado branco amorfo formado foi separado por filtração, lavado com pequenas frações de água gelada e depois com etanol e mantido num dessecador sob vácuo por uma noite, na presença de sílica gel. $\mathrm{O}$ rendimento foi de $20 \%$ tomando-se como referencial o $\mathrm{NaCl}$ de partida. Análise (calc) para $\mathrm{NaHCO}_{3}: \mathrm{C}=13,8 \%(14,3) ; \mathrm{H}=1,4 \%(1,2)$ e $\mathrm{N}=0,8 \%(0,0)$. A perda de massa por calcinação foi um pouco superior ao valor teórico, como esperado para uma amostra contaminada com $5,5 \mathrm{~mol} \%$ de $\mathrm{NH}_{4} \mathrm{Cl}$ (vide resultados de microanálise).

\section{RESULTADOS E DISCUSSÃO}

O liquor-mãe a partir do qual é precipitado o $\mathrm{NaHCO}_{3}$ (solubilidade a $0^{\circ} \mathrm{C}=69 \mathrm{~g} / \mathrm{L}$ ) contém grandes quantidades de íons $\mathrm{NH}_{4}{ }^{+}, \mathrm{Na}^{+}, \mathrm{Cl}^{-}$e $\mathrm{HCO}_{3}{ }^{-}$, que poderiam precipitar na forma de $\mathrm{NH}_{4}\left(\mathrm{HCO}_{3}\right)(120 \mathrm{~g} / \mathrm{L})$ e $\mathrm{NH}_{4} \mathrm{Cl}(298 \mathrm{~g} / \mathrm{L})$ juntamente com o produto desejado caso não houvesse um controle sobre a concentração de íons amônio em solução. Além disso, caso a solução resultante da carbonatação não estivesse saturada com $\mathrm{CO}_{2}$ ela seria alcalina, o que favoreceria a dissociação do bicarbonato a carbonato.

O arranjo descrito no presente artigo para simular o processo Solvay resulta de uma série de tentativas realizadas com o objetivo de otimizar tanto a pureza do produto obtido como o rendimento, além de reproduzir com fidelidade o processo industrial ${ }^{1}$. Por isso foi dada prioridade ao uso de duas colunas Vigreux para simular as torres de amoniação e carbonatação, com fluxo de gases em contra-corrente, utilizado na indústria. A pureza foi verificada por meio de microanálise e perda de massa por calcinação.

Após algumas tentativas concluimos que um arranjo experimental similar ao sugerido por Hooton ${ }^{7}$ seria o mais adequado. Porém, os resultados obtidos com esse arranjo não foram muito satisfatórios, principalmente devido a coprecipitação de bicarbonato de amônio. Logo ficou claro que esse problema decorria da inexistência de uma barreira que impedisse a mistura dos reagentes gasosos, gerando o referido sal em quantidade superior àquela necessária para saturar a solução. Além disso, tanto a reação de dissolução da amônia, como a reação do $\mathrm{CO}_{2} \mathrm{com}$ a solução saturada de $\mathrm{NaCl}$ e $\mathrm{NH}_{3}$ são exotérmicas, provocando um aquecimento substancial da solução. Esse aumento de temperatura faz com que a solubilidade dos reagentes gasosos diminua (principalmente $\mathrm{NH}_{3}$ ), provocando um declínio na eficiência do processo. Por exemplo, caso as colunas não fossem refrigeradas com água gelada, o rendimento seria muito baixo. Por outro lado, o aumento de temperatura provocado pela reação entre $\mathrm{NH}_{3}(\mathrm{aq})$ e $\mathrm{CO}_{2}(\mathrm{~g})$ e pela solvatação do $\mathrm{NH}_{3}(\mathrm{~g})$ fornece um bom indício sobre as posições nas colunas em que tais reações estão ocorrendo com maior intensidade. Assim, o fluxo de gases através da coluna foi controlado, de modo a manter a região mais quente a cerca de dois terços da altura a partir da base das colunas de carbonatação e amoniação, de modo a assegurar a saturação da solução com aqueles gases. Nessas condições otimizadas foi possível observar a formação de precipitado dentro de cerca de uma hora, quando a mistura reacional foi coletada num balão resfriado com gelo e água. Esse resultado foi inesperado, dadas as dificuldades descritas na literatura ${ }^{6}$ para observar a formação do sólido.

Foram encontrados alguns problemas para manter o elevado fluxo de $\mathrm{NH}_{3}(\mathrm{~g})$ requerido, mesmo utilizando uma grande quantidade de hidróxido de sódio ou potássio em pastilhas e solução concentrada de amônia, dada a elevada solubilidade desse gás em água ( 700 vol. de $\mathrm{NH}_{3}(\mathrm{~g}) / \mathrm{vol}$. de $\mathrm{H}_{2} \mathrm{O}$ a $0^{\circ} \mathrm{C}$ ). Por isso deve-se evitar borbulhar diretamente o gás amônia na solução, pois há o perigo de ocorrer o refluxo da solução. Logo, seria conveniente e recomendável a utilização de um cilindro de amônia, pois este permite um 
melhor controle sobre o processo, evitando oscilações no fluxo desse gás. Porém, não foram encontrados problemas muito sérios durante a utilização de gelo seco como fonte de $\mathrm{CO}_{2}$, mas o uso de um cilindro de $\mathrm{CO}_{2}$ pressurizado seria mais adequado.

Concluindo, é possível simular o processo Solvay utilizando a aparelhagem mostrada na figura 2 , construída a partir de vidrarias simples encontradas em qualquer laboratório. Os resultados obtidos foram excelentes e os tempos adequados para que esse importante processo industrial e os conceitos químicos envolvidos possam ser amplamente explorados numa aula experimental de 4 horas.

\section{REFERÊNCIAS}

1. Shreve, R. N.; Brink Jr., J. A. Chemical Process Industries; $4^{\circ}$ ed.; McGraw-Hill: N.Y., 1977; Cap. 13; Soda-Alcali Industries; Solvay Process, pág. 208.

2. Chem. Eng. News 1996, 24 junho, 40.

3. Anuários da Indústria Química Brasileira, ed. ABIQUIM, 1993.

4. Glanville, J.; Rau, E.; J. Chem. Educ. 1973, 50, 64.

5. Kirksey, H. G.; J. Chem. Educ. 1978, 55, 272.

6. Mckee, J. R.; Kauffman, J. M.; J. Chem. Educ. 1981, 58, 1035.

7. Hooton, A. W.; J. Chem. Educ. 1933, 10, 437. 